\title{
Age-Dependent Change of Tonic Immobility Response in Chicks of a Native Japanese Chicken breed, Tosa-Jidori
}

\author{
Eriko Nakasai ${ }^{1}$, Hiroshi Tanizawa ${ }^{1}$, Minani Takawaki ${ }^{1}$, Kouichi Yanagita ${ }^{1}$, Shin-ichi Kawakami ${ }^{1}$, \\ Takao Oka ${ }^{1,2}$, Masaoki Tsudzuki ${ }^{1,2}$ and Takashi Bungo ${ }^{1,2}$ \\ ${ }^{1}$ Department of Bioresource Science, Graduate School of Biosphere Science, Hiroshima University, \\ Higashi-Hiroshima 739-8528, Japan \\ ${ }^{2}$ Japanese Avian Bioresource Project Research Center, Hiroshima University, Higashi-Hiroshima 739-8528, Japan
}

\begin{abstract}
The objective of the present study was to evaluate the temperament of a native Japanese chicken breed (TosaJidori) using the tonic immobility test for the detection of fearfulness. Each chick (2, 5, 10 or 15-day old) was placed on its back on a table and restrained by hand. Thereafter, if the chick lay still, it was then released and observed. The number of inductions and tonic immobility duration was recorded. The duration in the male was shorter than that in the female at 2-day old, whereas higher than that in the female at 15-day old. The duration of tonic immobility was affected by age in the male $(P<0.05)$. There was a positive correlation between them in the male, and a negative correlation in the female. As for the number of induction, no significant differences and tendencies were found between sex and age. These findings demonstrate that Tosa-Jidori chicks show sexual differences in the fear response and further suggest that the temperamental differences may correspond to genetic characteristics of breeds.
\end{abstract}

Key words: chick, fear, stress, tonic immobility, Tosa-Jidori

J. Poult. Sci., 50: 321-325, 2013

\section{Introduction}

Over the last several decades, the selection of livestock has focussed intensely on production, which has caused a number of negative side effects on animal well-being. For instance, broilers tend to be too heavy for normal locomotion resulting to leg disorders. Because leg disorders are disabling and often associated with inflammation of joints, hocks and bone, it is clear that their incidence may cause a major welfare problem (Bradshaw et al., 2002). In order to improve sustainability, poultry breeders would also have to consider animal welfare. To that end, it is important to determine whether selection programs alter behavioral traits, which in turn could impair the adaptation of animals to husbandry systems.

Tonic immobility in birds has been used as an index of fearfulness and subjected to multifactorial and genetic analysis (Mills and Faure, 1986; Jones et al., 1994; MignonGrasteau et al., 2003). The reaction terminates spontaneously seconds to hours after induction when the animal rights itself. It may be a form of "pretended death," which is thought

Received: February 6, 2013, Accepted: March 18, 2013

Released Online Advance Publication: April 25, 2013

Correspondence: Dr. T. Bungo, Laboratory of Animal Behavior and Physiology, Graduate School of Biosphere Science, Hiroshima University, Higashi-Hiroshima 739-8528, Japan. (E-mail: bungo@hiroshima-u.ac.jp) to be useful in terms of confusing a potential predator (Tikal, 1991). It can be easily induced by a brief period of physical restraint and has been extensively studied in domestic fowls (Jones, 1986). Because an understanding of the temperament of specific animal breeds may aid the selection of animals for welfare and handling, several genetic selection programs have been set up for different fear-related behavioral traits in birds (Mills and Faure, 1991). For example, the relationship between feather pecking and the duration of tonic immobility, a traditional measure of fearfulness in poultry (Gallup, 1977), has been studied more than that between feather pecking and tonic immobility (e.g., Vestergaard et al., 1993). To consider animal welfare, genetic selection for preventing abnormal behavior could be performed by tonic immobility duration as a breeding goal.

During the early 1990's, scientists and livestock producers became particularly concerned about the potential loss of indigenous breeds, and a programme was launched by the FAO for the genetic conservation of poultry resources (FAO, 2007). Japan has a great variety of indigenous chicken bioresources (approximately 50 breeds), and almost all of them were developed for special plumage, crowing and fighting traits (Tsudzuki, 2003), as opposed to European and American breeds that were mostly established for meat and egg production. However, the study of Japanese native breeds as genetic resources has received very little scientific attention, 
and current research efforts have been directed primarily towards enhancing not only commercial production systems, but also animal welfare.

Tosa-Jidori is believed to have lived in Japan for more than 2000 years, and to be the oldest type of Japanese native chicken. The standard body weight in adults is $675 \mathrm{~g}$ for males and $600 \mathrm{~g}$ for females. This breed has a single comb, red earlobes and yellow shanks (Tadano et al., 2008). The aim of this study was to survey the temperament of TosaJidori, using the tonic immobility test for the detection of fearfulness, in order to use valuable indigenous bioresources for improving commercial chickens.

\section{Materials and Methods}

\section{Animals}

The data were collected from a Japanese chicken breed, the indigenous Tosa-Jidori breed, which are kept at our institute. The number of chicks for each sex was eight to ten. The birds were maintained in a room with 24-h lighting and at a temperature of $32^{\circ} \mathrm{C}$ for the 1 st week and $29^{\circ} \mathrm{C}$ for the 2nd week. They were housed in wooden cages with a wiremesh floor $(18 \times 25 \times 20 \mathrm{~cm})$ at a population density of 4 chicks per cage, and given free access to a commercial starter diet and water during the experimental period. Birds were not touched by any caretaker, except daily measurement of body weight. The handling of birds was performed in accordance with the regulations of the Animal Experiment Committee of Hiroshima University.

\section{Tonic Immobility Test}

Tonic immobility test was performed at the age of 2, 5, 10 and $15 \mathrm{~d}$ according to modified methods described by Heiblum et al. (1998). Briefly, each chick was gently taken from their cages at random, and tested individually and only once in a separate room. It was placed on its back on a table covered with a newspaper and restrained for $15 \mathrm{~s}$, (one hand over the body and one over the head). Towards the end of the $15 \mathrm{~s}$ period, the hand was gradually lifted. If the chick still moved, another induction period of $15 \mathrm{~s}$ is started, until movement ceased. When the chick finally laid still, it was then released and observed from a position a meter away (Gallup, 1977). The number of inductions and tonic immobility duration were recorded. When the immobility duration was less than $5 \mathrm{~s}$, additional induction trials of $15 \mathrm{~s}$ each were conducted, up to a maximum of four trials. Scores

Table 1. Body weights $(\mathrm{g})$ in native Japanese Tosa-Jidori breed chicks

\begin{tabular}{lll}
\hline \multicolumn{1}{c}{ Age } & \multicolumn{1}{c}{ Male } & \multicolumn{1}{c}{ Female } \\
\hline 2-day old & $23.3 \pm 0.5(8)$ & $23.5 \pm 0.5(10)$ \\
5-day old & $23.9 \pm 0.5(10)$ & $22.8 \pm 0.7(8)$ \\
10-day old & $29.4 \pm 2.2(8)$ & $27.5 \pm 0.9(8)$ \\
15-day old & $33.4 \pm 1.6(8)$ & $32.2 \pm 1.7(9)$ \\
\hline
\end{tabular}

Values are means \pm SEM of the number of chicks in parentheses. of zero for tonic immobility were given to chicks after four unsuccessful induction trials, whereas maximum of five is given for the corresponding number of inductions. If the bird remained in tonic immobility over the $10 \mathrm{~min}$ testing period, maximum scores of $600 \mathrm{~s}$ were scored for tonic immobility duration. After test, birds were reterned to the original cages. Table 1 shows that body weights of birds used for data analysis. The weights were normal in each day age of TosaJidori (Goto et al., 2010). The number of birds used for data analysis is shown in each table.

\section{Statistical Analysis}

The data were analyzed using the commercially available package, StatView (SAS Institute, Cary, USA, 1988). For analysis of the duration of tonic immobility, ANOVA was used to determine statistical significance due to sex and age of chicks. When the effect was significant, the TurkeyKramer test was used to compare the significance among means. Correlation between the duration of tonic immobility and age of chicks was analyzed using the Pearson's productmoment correlation method. For the induction, the values were compared using the nonparametric test of MannWhitney and the Kruskal-Wallis test with the Steel-Dwass test for pairwise comparisons. Statistical significance was set at $\mathrm{P}<0.05$. Results are presented as means \pm SEM.

\section{Results}

The tonic immobility test was succeeded in all trials except for one case involving a 2-day old which was given scores of zero for tonic immobility duration, and of five for number of inductions. There were two females at 2-day old, which were scored $600 \mathrm{~s}$ but other chicks righted themselves within the 10 min-testing period.

Table 2 shows that duration of tonic immobility in chicks. Comparing each age by sexes, the duration in males tended to be shorter than that in the female at 2-day old $(P=0.08)$, whereas the value in the male at 15-day old tended to be twice as high as in the female $(P=0.07)$. The duration of tonic immobility was not significantly affected by age in the female $(P>0.1)$ but was affected in the male $(P<0.05)$. The duration at 9-day old was significantly shorter than that at 15day old which was the longest immobility duration observed in the male.

The relationship between duration and age in each sex is shown in Figure 1. Statistical analysis demonstrated a posi-

Table 2. Duration (sec) of tonic immobility in native Japanese Tosa-Jidori breed chicks

\begin{tabular}{ccc|c}
\hline \hline \multicolumn{1}{c|}{ Age } & Male & Female & ANOVA \\
\hline 2-day old & $112 \pm 31^{\mathrm{ab}}(8)$ & $272 \pm 73(10)$ & $P=0.08$ \\
5-day old & $135 \pm 27^{\mathrm{ab}}(10)$ & $223 \pm 64(8)$ & $P=0.19$ \\
10-day old & $107 \pm 27^{\mathrm{a}}(8)$ & $105 \pm 23(8)$ & $P=0.96$ \\
15-day old & $249 \pm 51^{\mathrm{b}}(8)$ & $123 \pm 41(9)$ & $P=0.07$ \\
\hline ANOVA & $P=0.03$ & $P=0.12$ & \\
\hline
\end{tabular}

Values are means \pm SEM of the number of chicks in parentheses. Means with different letters are significantly different at $P<0.05$. 
tive correlation between them in the male, and the duration got longer with aging $(r=0.391 ; P<0.05)$. Meanwhile a negative correlation was found in the female, and the duration got shorter with aging $(r=-0.371 ; P<0.05)$.

The number of induction required to produce tonic immobility in chicks of native Japanese chicken breed, TosaJidori is shown in Table 3. Most of the observed scores were scores of one and all means in the tonic immobility test indicated scores of less than two. No significant differentiations and tendencies were found between sex and age.

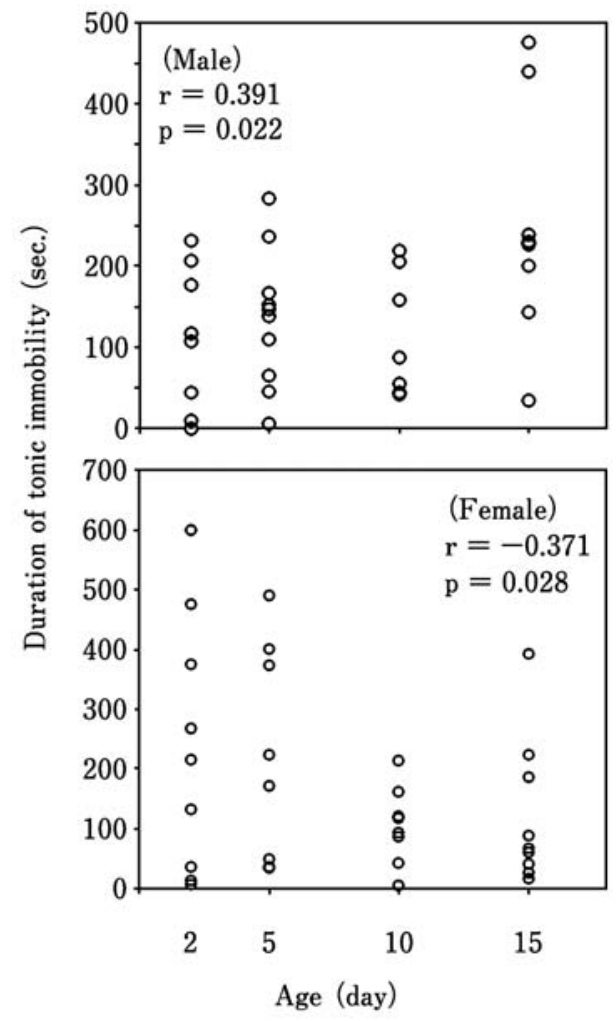

Fig. 1. Correlations between the duration of tonic immobility and age in the male (upper panel) and female (lower panel) of chicks of a native Japanese chicken breed, Tosa-Jidori. The correlations between the immobility duration and age were certified $(P<0.05)$.

\section{Discussion}

We surveyed the early development of the tonic immobility response, which is considered to be a measure of the animal's innate fearfulness (Jones, 1986). The present results show that the response could be found at the first week of life in chicks. These findings are in agreement with previous reports showing that the tonic immobility could be elicited by dorsal induction as early as the first day of life in White Leghorn chicks (Heiblem et al., 1998). On the contrary, there were earlier reports demonstrating that tonic immobility response is absent before 7-10 day old (Ratner and Thompson, 1960; Salzen, 1963). One possible reason is strain differences in the expression of emotion (Gallup et al., 1976), and therefore, genetic differences that influence the development of fear (Phillips and Siegel, 1966) which could account for opposite findings because they used broiler (Cobb) or crossbreed (Brown Leghorn $\times$ Light Sussex) chicks (Phillips and Siegel, 1966).

It is reported that the tonic immobility response was strongly affected by age (Heiblem et al., 1998). They showed that although poorly developed during the first three days of life in Leghorn males, the response could be elicited by dorsal induction as early as the first day of life and was much enhanced between the third and fifth days. Similarly, the duration increased with aging in the male Tosa-Jidori chick. However, in the female, it decreased with aging, and therefore, the development of tonic immobility response might be different according to sex. These results were supported by Jones (1979) who found that the domestic chick is thought to show sex differences in timidity tests. In an assessment of tonic immobility as fearfulness, which commonly correlates with high immobility durations (Jones, 1996), the male would be more sensitive than the female. It was reported that high fear reactions are often associated with high susceptibility to stress in quails (Jones et al., 1992; Mills and Faure, 2000).

As to the number of induction, which is also a parameter for fear (Faure et al., 1983; reduced the induction score), we could not find any significant effects of both sex and age in this experiment. These results disagreed with previous studies indicating that the numbers of induction gradually decreased with age (Heiblem et al., 1998). Thus, this score might be not useful for use as fear index in Tosa-Jidori

Table 3. Induction score in native Japanese Tosa-Jidori breed chicks

\begin{tabular}{llc|c}
\hline \multicolumn{1}{c}{ Age } & \multicolumn{1}{c|}{ Male } & Female & Mann-Whitney \\
\hline 2-day old & $1.9 \pm 0.5(8)$ & $1.7 \pm 0.3(10)$ & $P=0.88$ \\
5-day old & $1.0 \pm 0(10)$ & $1.5 \pm 0.3(8)$ & $P=0.10$ \\
10-day old & $1.3 \pm 0.2(8)$ & $1.5 \pm 0.2(8)$ & $P=0.32$ \\
15-day old & $1.5 \pm 0.3(8)$ & $1.4 \pm 0.3(9)$ & $P=0.90$ \\
- Kruskal-Wallis & $P=0.24$ & $P=0.70$ & \\
\hline
\end{tabular}

Values are means \pm SEM of the number of chicks in parentheses. 
chicks.

Several genetic selections for fear-related traits have since been conducted in birds (Gallup, 1974, Mills and Faure, 1991). Vestergaard et al. (1993) reported that individual red jungle fowl that feather pecked the most were the ones found to be the most fearful as assessed by the duration of tonic immobility. Blokhuis and Beutler (1992) found that laying hens showing high feather pecking showed a longer tonic immobility response than those with low feather pecking. To consider animal welfare, selection against long tonic immobility duration should prevent high feather pecking. Interestingly, several quantitative trait loci (QTL) have been identified in chicken for tonic immobility, which is linked to three QTLs on chromosome 1 (Schütz et al., 2004). During domestication, selection for increased growth and egg production in chicken might have simultaneously caused selection for modifications in social behavior and emotionality because of a major QTL on chromosome 1 which is identified to influence both production and behavioral traits (Wiren and Jensen, 2011). In fact, some studies have indicated relationships between the propensity to express fear responses and feed efficiency traits. For example, the most efficient and productive hens and broilers have been found to exhibit the lowest fear reactions to humans (Barnett et al., 1992; Hemsworth et al., 1994; Hemsworth and Barnett, 1989). From the viewpoint of not only welfare but also productivity, tonic immobility is useful for improving the birds' ability to adapt to challenges.

These findings demonstrate that chicks of a native Japanese chicken breed, Tosa-Jidori, show sexual differences in the fear response and suggest that the temperamental differences may correspond to genetic characterization of breeds. There is a possibility that early development of tonic immobility is a useful tool for early screening for selection of low-fear birds. Further work on the behavioral characteristic tests is necessary for the selection of animals for both welfare and productivity.

\section{Acknowledgment}

The authors are grateful to Dr. L.M. Liao for proofreading the manuscript.

\section{References}

Barnett JL, Hemsworth PH and Newman EA. Fear of humans and its relationships with productivity in laying hens at commercial farms. British Poultry Science, 33: 699-710. 1992.

Blokhuis HJ and Beutler A. Feather pecking damage and tonic immobility response in two lines of White Leghorn hens. Journal of Animal Science, 70 (Suppl. 1): 170. 1992.

Bradshaw RH, Kirkden RD and Broom DM. A review of the aetiology and pathology of leg weakness in broilers in relation to welfare. Avian and Poultry Reviews, 13: 45-103. 2002.

FAO. The State of the World's Animal Genetic Resources for Food and Agriculture. (Rischkowsky B. and D. Pilling, eds.), Rome. 2007.

Faure JM, Jones RB and Bessei W. Fear and social motivation as factors in open-field behaviour of the domestic chick. Behavioral Biology, 8: 103-116. 1983.
Gallup Jr GG. Genetic influence on tonic immobility in chickens. Animal Learning and Behavior, 2: 145-147. 1974.

Gallup Jr GG. Tonic immobility: the role of fear and predation. Psychological Record, 27: 41-61. 1977.

Gallup Jr GG, Ledbetter DH and Maser JD. Strain differences among chickens in tonic immobility: evidence for an emotionality component. Journal of Comparative and Physiological Psychology, 90: 1075-1081. 1976.

Goto T, Goto N, Shiraishi J, Bungo T and Tsudzuki M. Comparison of growth curves for four breeds of Japanese native chicken, Onaga-dori, Tosa-jidori, Ukokkei and Hinai-dori. Journal of Animal and Veterinary Advances, 9: 1362-1365. 2010.

Heiblum R, Aizenstein O, Gvaryahu G, Voet H, Robinzon B and Snapir N. Tonic immobility and open field responses in domestic fowl chicks during the first week of life. Appled Animal Behaviour Science, 60: 347-357. 1998.

Hemsworth PH and Barnett JL. Relationships between fear of humans, productivity and cage position of laying hens. British Poultry Science, 30: 505-518. 1989.

Hemsworth PH, Coleman GJ, Barnett JL and Jones RB. Behavioural responses to humans and the productivity of commercial broiler chickens. Appled Animal Behaviour Science, 41: 101-114. 1994.

Jones RB. The hole-in-the-wall test: its validity as a measure of the 'timidity' aspect of fear in the domestic chick. IRCS Medical Science, 7: 167. 1979.

Jones RB. The tonic immobility reaction of the domestic fowl: a review. World's Poultry Science Journal, 42: 82-97. 1986.

Jones RB. Fear and adaptability in poultry: insights, implications and imperatives. World's Poultry Science Journal, 52: 131174. 1996.

Jones RB, Mills AD, Faure JM and Williams, JB. Restraint, fear, and distress in Japanese quail genetically selected for long or short tonic immobility reactions. Physiology and Behavior, 56: 529-534. 1994.

Jones RB, Satterlee DG and Ryder FH. Fear and distress in Japanese quail chicks of two lines genetically selected for low or high plasma corticosterone response to immobilization stress. Hormone and Behaviour, 26: 385-393. 1992.

Mignon-Grasteau S, Roussot O, Delaby C, Faure JM, Mills A, Laterrier C, Guemene D, Constantin P, Mills M, Lepape G and Beaumont C. Factorial correspondence analysis of fear-related behaviour traits in Japanese quail. Behavioural Processes, 61: 69-75. 2003.

Mills AD and Faure JM. The estimation of fear in domestic quail: correlations between various methods and measures. Biology Behavior, 11: 235-243. 1986.

Mills AD and Faure JM. Divergent selection for duration of tonic immobility and social reinstatement behavior in Japanese quail (Coturnix coturnix japonica) chicks. Journal of Comparative Psychology, 105: 25-38. 1991.

Mills AD and Faure JM. Ease of capture in lines of Japanese quail (Coturnix japonica) subjected to contrasting selection for fear or sociality. Appled Animal Behaviour Science, 69: 125-134. 2000.

Phillips RE and Siegel PB. Development of fear in chicks of two closely related genetic lines. Animal Behaviour, 14: 84-88. 1966.

Ratner SC and Thompson RW. Immobility reactions (fear) of domestic fowl as a function of age and prior experience. Animal Behaviour, 8: 186-191. 1960.

Salzen EA. Imprinting and the immobility reactions of domestic 
fowl. Animal Behaviour, 11: 66-71. 1963.

Schütz K, Kerje S, Jacobsson L, Forkman B, Carlborg Ö, Andersson $\mathrm{L}$ and Jensen P. Major growth QTLs in fowl are related to fearful behavior: possible genetic links between fear responses and production traits in a red junglefowl $\times$ White Leghorn intercross. Behavior Genetics, 34: 121-130. 2004.

Tadano R, Nishibori M, Imamura Y, Matsuzaki M, Kinoshita K, Mizutani M, Namikawa $\mathrm{T}$ and Tsudzuki M. High genetic divergence in miniature breeds of Japanese native chickens compared to Red Junglefowl, as revealed by microsatellite analysis. Animal Genetics, 39: 71-78. 2008.

Tikal K. Tonic immobility and factors influencing its duration in rats. Homeostasis, 33: 199-203. 1991.

Tsudzuki M. Japanese native chickens. In: The Relationship between Indigenous Animals and Humans in APEC Region. (Chang, H.L. and Y. C. Huang, eds.) The Chinese Society of Animal Science, Taiwan. pp. 91-116. 2003.

Vestergaard KS, Kruijt JP and Hogan JA. Feather pecking and chronic fear in groups of red junglefowl: their relations to dustbathing, rearing environment and social status. Animal Behaviour, 45: 1127-1140. 1993.

Wiren A and Jensen P. A growth QTL on chicken chromosome 1 affects emotionality and sociality. Behavior Genetics, 41: 303311. 2011. 